\title{
Symmetry during the take-off phase of countermovement jump in fencers
}

Dagmara IWAŃSKA*1 ${ }^{*}$, Piotr TABOR ${ }^{1}$, Ewa POLAK ${ }^{2}$, Magdalena KARCZEWSKA ${ }^{1}$, Anna MADEJ1, Andrzej MASTALERZ ${ }^{1}$, \& Czesław URBANIK ${ }^{1}$

${ }^{1}$ Józef Piłsudski University of Physical Education in Warsaw (Poland)

${ }^{2}$ University of Rzeszow (Poland)

5th IMACSSS World Scientific Congress Abstracts, Rio Maior (Portugal), October 6-8

Section: Biological, kinesiological and physiological aspects of MA\&CS Type: Oral communication

\section{Introduction}

Symmetry in the motion of the left and right sides of the body has important practical significance for the everyday functioning as well as sport actions. The way of human movement symmetry evaluation is still a scientific question (Maloney, Fletcher, \& Richards, 2015; Bailey, Sato, Burnett, \& Stone, 2015). Many scientists noted that it could be a predicate of injury and indicator of therapy progress (An, Wong, \& Cheung, 2015; Doherty, et al., 2016). Calculation of symmetry indicators that are based on biomechanical variables in static conditions does not raise any objections (Wit, 2012). Difficulties arise when we want to measure variables in dynamic conditions. One of the most often used motor task that allows identifying and analyzing biomechanical variables, such as ground reaction force, is vertical jump with arms swing, called countermovement jump (CMJ). Therefore, the aim of this study is to evaluate symmetry during the take-off phase of CMJ in training cycle of fencers. The results of ground reaction forces analysis can be used as a predicate of injury.

\section{Methodology}

Four male fencers from the AZS-AWF Warszawa sport club participated in the study. They had the following characteristics: height $181 \pm 4.6 \mathrm{~cm}$, body mass $74 \pm 7.3 \mathrm{~kg}$, age $22 \pm 2.6$ years, and sport experience $12 \pm 3.3$ years. The study included double measurement. The first one was made at the beginning of the preparatory phase of macrocycle, and the second measurement was taken three months later, at the beginning of the competitive phase of the same macrocycle. All subjects performed three countermovement jumps with interval among them lasting 5 seconds. In starting and ending positions subjects stood on two force plates (separate plates under each foot). Ground reaction force were collected using a Kistler force plate with a sample rate of $200 \mathrm{~Hz}$. Average drawing ground reaction force came into three trials in such way that total force impulse remained invariable (1). On the basis of the sum of left and right force, analyzed movement was divided into two parts: the phase I - from the beginning to the obtained minimum value of $\mathrm{F}_{\mathrm{z}}$, and the phase II from the end of the phase I to the obtained local maximum of $\mathrm{F}_{\mathrm{z}}$. Such division was made because for each subject, the curves on the graphs of force were characterized by the only one maximum value. For both movement phases Pearson correlation coefficient ( $r$ ) and relative asymmetry index (RAI) between right and left force (2) were calculated.

$\int_{t_{0}}^{t_{k}} F_{1} d t=\int_{t_{0}}^{t_{a v}} F_{1}^{\prime} d t$

$t_{0}-t_{k}$ - trial time; $t_{0}-t_{a v}$ - average time; $F_{1}$ - ground reaction force; $F_{1}$ ' - ground reaction force after transformation.

$$
R A I=\frac{\bar{x}}{Y} 100 \%
$$

$\bar{x}_{-}$the average difference between the values noted for the right and left extremities in a given phase; $Y$ - total range of motion of the changes in the given phase (absolute value of the difference between the largest and the smallest ground reaction force for a given phase of motion) (Forczek \& Staszkiewicz, 2012). 
Additionally symmetry index, which is equal $S I=2\left(R_{L}-R_{R}\right) /\left(R_{L}+R_{R}\right) 100 \%$ was calculated (Wit, 2012). This factor was calculated for minimum value of ground reaction force $\left(R_{\min }\right)$ and local maximum force $\left(\mathrm{R}_{\max }\right)$. To the overall assessment of symmetry the own multidimensional index was proposed. This index, called symmetry vector ( $\vec{s})$, was calculated according to the formula $\overrightarrow{S I}=\left[\begin{array}{lll}r & R A I & S I\end{array}\right]$ where first coordinate ( $\mathrm{r}$ - Pearson correlation coefficient) indicates similar character of ground reaction force, second ( $R A I$ - relative asymmetry index) is the average size of distance between curves, and third is symmetry index (SI) for the selected measuring points. For the total movement the symmetry vector is two-dimensional: $\overrightarrow{S I}=[r R A I]$. In contrast, for the first and the second phase it is three-dimensional: $\overrightarrow{S I}=\left[\begin{array}{llll}r_{1} & R A I_{1} & S I_{1}\end{array}\right]$ and $\overrightarrow{S I}=\left[\begin{array}{lll}r_{2} & R A I_{2} & S I_{2}\end{array}\right]$. It was assumed that the asymmetry occurs when indicators RAI and SI are higher than 10\% (Wit, 2012).

\section{Results}

Tested fencers, in both the beginning and the end of the preparatory phase of macrocycle, were characterized by symmetry in the take-off phase of CMJ. General symmetry vector equalled respectively of $[0.99 ; 2 \%]$ in the beginning, and $[0.99 ; 4 \%]$ in the end of the training cycle. For the phase I of CMJ, from the beginning to achieve a minimum ground reaction force, vectors were different due to indexes $R A I$ and SI. They were [0.99; 5\%; 11\%] in the beginning of the training cycle and [0.98; 9\%; 28\%] in the second measurement. In the phase II of CMJ, there were no so significant differences (in the beginning of the cycle $[0.99,4 \%, 2 \%]$, and $[0.99,7 \%, 2 \%]$ after its completion).

\section{Discussion and conclusion}

Taking into account that the typical movement performed by the athletes in fencing is usually asymmetrical, observed symmetry of ground reaction force came as a surprise. Pearson correlation coefficients indicate almost identical nature of the curves describing the vertical ground reaction forces. RAI index, which also indicates the distance between the curves, points as well to their high similarity. Only a minimum of ground reaction forces (during the relief pressure of the body) showed slight asymmetry at the first measurement (11\%) and no longer significant after three months (28\%). It can be argued that after three months of the preparatory phase of macrocycle in tested fencers asymmetry was not found in the take-off phase of CMJ. Moreover, the use of the above methods to assess the symmetry of athletes' movement requires further research.

\section{References}

An, W. W., Wong, V., \& Cheung, R. T. H. H. (2015). Lower limb reaction force asymmetry in rowers with and without a history of back injury. Sports Biomechanics, 14(4), 375-83.

Bailey, C. A., Sato, K., Burnett, A., \& Stone, M. H. (2015). Force-Production Asymmetry in Male and Female Athletes of Differing Strength Levels. International Journal of Sports Physiology and Performance, 10(4), 504-508.

Doherty, C., Bleakley, C., Hertel, J., Caulfield, B., Ryan, J., Sweeney, K., Patterson, M. R., \& Delahunt, E. (2016). Coordination and Symmetry Patterns During the Drop Vertical Jump in People With Chronic Ankle Instability and Lateral Ankle Sprain Copers. Physical Therapy, 96(8), 1152-1161.

Forczek, W., \& Staszkiewicz, R. (2012). An evaluation of symmetry in the lower limb joints during the able-bodied gait of women and men. Journal of Human Kinetics, 35(December), 47-57.

Maloney, S. J., Fletcher, I. M., \& Richards, J. (2016). A Comparison of Methods to Determine Bilateral Asymmetries in Vertical Leg Stiffness. Journal of Sports Sciences, 34(9), 829-35.

Wit, A. (Ed.). (2012). Wartości normatywne do oceny asymetrii chodu i postawy stojącej czlowieka. Warszawa: Akademia Wychowania Fizycznego Józefa Piłsudskiego.

Key words: Biomechanics; lower extremity; symmetry; vertical jump; combat sports; fencing.

Study supported by the project of Polish Ministry of Science and Higher Education "The development of academic sports": RSA2 00952 (PB-81). 